\title{
Public Perceptions of Electroconvulsive Therapy: A Historic Review
}

Steven M. Jenkusky, M.D.

University of New Mexico, Albuquerque. New Mexico

Follow this and additional works at: https://jdc.jefferson.edu/jeffjpsychiatry

Part of the Psychiatry Commons

Let us know how access to this document benefits you

\section{Recommended Citation}

Jenkusky, M.D., Steven M. (1992) "Public Perceptions of Electroconvulsive Therapy: A Historic Review," Jefferson Journal of Psychiatry. Vol. 10 : Iss. 2 , Article 3.

DOI: https://doi.org/10.29046/JJP.010.2.001

Available at: https://jdc.jefferson.edu/jeffjpsychiatry/vol10/iss2/3

This Article is brought to you for free and open access by the Jefferson Digital Commons. The Jefferson Digital Commons is a service of Thomas Jefferson University's Center for Teaching and Learning (CTL). The Commons is a showcase for Jefferson books and journals, peer-reviewed scholarly publications, unique historical collections from the University archives, and teaching tools. The Jefferson Digital Commons allows researchers and interested readers anywhere in the world to learn about and keep up to date with Jefferson scholarship. This article has been accepted for inclusion in Jefferson Journal of Psychiatry by an authorized administrator of the Jefferson Digital Commons. For more information, please contact: JeffersonDigitalCommons@jefferson.edu. 


\title{
Public Perceptions of Electroconvulsive Therapy: A Historic Review
}

\author{
Steven M. Jenkusky, M.D.
}

\begin{abstract}
Electroconvulsive therapy, an effective treatment for depression, mania and some forms of schizophrenia, has had a tumultuous and controversial history. The dramatic nature of the therapy as well as its use in the mentally ill in a seemingly indiscriminate manner has historically captured the public's attention and concern. The evolution of this therapy and the public and psychiatric profession's responses to it are reviewed here. Often the public's understanding of the therapy, how it is administered, its applications and side effects have lagged behind how the psychiatric profession views ECT, although at times mental health professionals have remained opposed to the therapy despite current research finding. At present, ECT appears to be experiencing a resurgence, with little active opposition.
\end{abstract}

Electroconvulsive Therapy (ECT), formerly referred to as electroshock or shock therapy is one of the most controversial medical therapies. This controversy stems from many factors: the dramatic nature of the therapy, using electricity to induce seizures; its use on mentally-ill patients, with the question of proper and adequate informed consent; and the serious side effects and perceived abuses associated with the use of ECT in the past. Few, if any, other medical therapies seem to capture as much of the public's attention, and generate as much emotional debate.

This paper reviews the public's response to the use of this therapy as reflected in popular magazine articles published since EGT became a common therapy in the 1940's. The scientific validity of this therapy will not be assessed, although the reaction of the psychiatric profession to public scrutiny will be noted.

The discovery of ECT was based on the observation that catatonics and other schizophrenic patients would temporarily lose their psychotic symptomatology after a spontaneous seizure of any cause (1). In Hungary, a psychiatrist, Von Medula hypothesized that intentionally induced seizures might ameliorate schizophrenic symptoms. In 1934, he injected camphor intramuscularly into a patient to induce a seizure. The patient, in a catatonic stupor for four years, reportedly recovered after several treatments. Von Medula then treated 26 additional schizophrenic patients that year, with successful outcomes in about half (2).

Hence convulsive therapy was born, and spread rapidly throughout Europe. Coincidentally, two other dramatic forms of psychiatric therapy were introduced at this time: insulin coma therapy by Sakel in 1933, and psychosurgery by Moniz in 1935 (1). Insulin coma therapy involved the intentional induction of hypoglycemic coma in 
a patient by the injection of insulin, followed, after several hours, with intravenous glucose and recovery from the coma. Psychosurgery involved performing actual surgery on the patient's cerebrum (the frontal lobotomy) in an attempt to alleviate psychiatric symptoms. The development of these three treatments caused much excitement in the field of psychiatry. To this point, very little was available in the way of somatic or pharmacological treatments for the mentally ill. As a result, these therapies were eagerly embraced by the profession $(2,3)$.

However, the use of chemicals to induce seizures produced extreme discomfort for patients, especially during the period between the injection of the medication and the actual convulsion. Thus, an effort was made to find an alternative method of induction. Seizures were known to be inducible in dogs by electrical stimulation of the exposed brain, and it was theorized that the same could be induced extracerebrally, by electrodes, in humans (2).

In Italy, Cerletti and Bini experimented with dogs and found that seizures could be induced by electric current applied through electrodes placed in the mouth and rectum, but numerous fatalities occurred. When the electrodes were placed on the temples of the dogs, fatalities were eliminated as long as the duration of exposure did not result in respiratory depression (1). Cerletti and Bini became convinced that this approach would be safe for humans, yet it was with apparent trepidation that the first treatment was given. In 1938, a candidate for treatment was found. A 38-year-old man who was found wandering the streets of Rome, alternately mute and talking incomprehensibly. He was hospitalized and after several weeks of observation a diagnosis of schizophrenia was made, and the first electroconvulsive treatments were given. The first stimulus was cautiously applied, but was inadequate to cause a seizure. The researchers reported that just prior to the second attempt, the patient stated clearly, "Not another, it will kill me!" (This admonition by the first recipient of ECT has been often quoted by its opponents) (3). A second treatment was applied though, precipitating a grand mal seizure, and unconsciousness. On awakening, the patient was apparently aware and capable of lucid communication. Full recovery followed after 11 treatments (3).

The apparent safety and ease with which convulsions could be stimulated by electrical means constituted a major advance for psychiatry, and was quickly embraced by the profession. Initially the treatment was used for schizophrenic patients exclusively, but in time, ECT was tried for a variety of mental illnesses. Ultimately it was found to be primarily effective for major depression (3).

When initially used through the 1940's, ECT clearly had dangerous side effects; from the seizure itself, fractures including the spine and muscle injuries could occur (1). Also the prospect of being subjected to an electric shock and seizure while fully awake was terrifying to patients and traumatic to the staff administering the therapy (4). The experience of receiving ECT was described in the book "The Bell Jar" by Sylvia Plath (5). Also the book and subsequent film, "One Flew Over the Cuckoo's Nest" in 1975, graphically pictured ECT as a barbaric, terrifying therapy. Much as insulin coma and psychosurgery fell into disrepute within 15-20 years, these side 
effects and apparent abuses further eroded the public's confidence in ECT as a viable treatment option by its critics (4).

An article in Time magazine in 1947 stated that in the case of ECT, the "cure may be worse than the disease" (6). The article pointed out that the convulsions could dislocate the patient's jaw, break his bones, or even kill him. A group of psychiatrists were cited as saying that the treatment had become a fad, being greatly overused as a "cure all" for too many mental illnesses.

Two subsequent Newsweek articles, both in 1949, presented a positive case for ECT, without mention of the above side effects $(7,8)$. The articles discussed the results of studies by psychiatrists which indicated ECT was very effective with rare side effects. Despite these apparent good results, one psychiatrist did admit that ECT was still on trial in both the lay and medical press, and the controversy was harming psychiatric progress.

However, by the early 1950 's, ECT was modified, eliminating the danger of skeletal and muscle injuries, and greatly reducing the pain, discomfort and anxiety that accompanied the therapy in the 30's and 40's. Muscle relaxants were given to prevent muscle spasms during the seizure, and the patient was placed under anesthesia before delivering the stimulus (2). Patients then underwent therapy while unconscious, awakening with, at most, a mild headache and transient confusion (9). Subsequently it was found that some memory loss could occur (9), and this became a new focus for concern and controversy (10).

Through the 1950's and 1960's, very little national attention was given to ECT, perhaps as response to the institution of general anesthesia and muscle-relaxing drugs for the prevention of side-effects from ECT. Also tricyclic antidepressant medication was introduced at this time, resulting in increased interest in the pharmacologic treatment of depression (2).

In 1971, a thinly disguised autobiographical account of a woman who suffered from depression and subsequently received ECT was published in America. "The Bell Jar" by Sylvia Plath (5), graphically described depression and its treatment in the early 1950's. She received a total of six ECT treatments, however, the first was by a psychiatrist who had not yet adopted the practice of administering anesthesia prior to applying the electrical stimulus.

She describes the experience as follows:

Then something bent down and took hold of me and shook me like the end of the world. Whee-ee-ee-ee-ee, it shrilled, through an air crackling with blue light, and with each flash a great jolt drubbed me till I thought my bones would break and the sap fly out of me like a split plant. I wondered what terrible thing it was that I had done (5).

After this initial, terrifying experience, the patient was admitted to a psychiatric facility with a different psychiatrist, who administered ECT with anesthesia. The procedure was then described after the initial fear was overcome as being relatively benign, with the patient recovering from the depressive episode. Nonetheless, as late as 1980 the description of the initial ECT treatment was commonly cited by critics as an example of the inhumanity and barbarous nature of the therapy (11). 
Electroconvulsive therapy was brought back under public scrutiny in the early 1970 's, with the controversy surrounding the mental health of presidential candidate George McGovern's running mate, Senator Thomas Eagleton. It became known that Eagleton had been hospitalized for "nervous exhaustion and fatigue" on three separate occasions in the 1960's, and on two of these admissions he received ECT treatments (12). The furor that resulted eventually caused him to withdraw from the ticket, and seemed to raise public questions about ECT, to the point that the American Psychiatric Association convened a panel of experts to help handle press inquiries about depression and its treatment (13).

Several articles were published on depression and its treatment $(14,15)$. One consisted of interviews with patients who had undergone ECT for depression, and their feelings about the illness and therapy (14). All interviewed were positive and thankful for the effectiveness of their treatment and generally expressed sympathy for Eagleton's predicament. These articles also briefly described the history of ECT and what the procedure of administering the therapy involved. In addition, the side effect of memory loss was publicly mentioned for the first time. And, as it is often pointed out, the fact that the mechanism by which ECT is effective is unknown, was again highlighted.

In 1975, the New Yorker published an extensive account of a woman who was suffering from depression and was given a course of eight ECT treatments (16). As a result her depression lifted; however, she continued to suffer memory loss occurring after the treatment. The memory loss apparently was quite extensive, ranging from both short-term, i.e., not knowing how she came to be in a mental institution, to forgetting essentially how to do her job as an economic analyst for the federal government. This article went on to discuss the historical development of ECT, beginning with a discussion of an eighteenth century notion that a cure for certain mental illnesses could be effected by "shocking" or frightening the patient. These methods for shocking included suddenly hurling an unsuspecting patient into a pond, or awakening him to a stimulated ghostly apparition. The objective was to "shock" the patient back to reality (16). From this introduction the author went on to describe other forms of shock therapy including chemotherapeutic approaches, such as intentionally infecting the patient to precipitate an "explosively curative" fever, and the use of insulin to induce a hypoglycemic coma. From here he embarks on a description of the discovery of ECT by Cerletti and Bini, and how ECT was currently administered (16). He relates the patient's description of awakening from treatment as follows: "There is a harrowing sense of confusion, then a full awakening in the midnight dark of total amnesia." The gradual return of memory is described, from the distant past almost to the present, the most recent weeks being described as almost always irretrievable (16). The patient described in the article then discussed the difficulties of returning to her normal life with an incomplete memory. Compounding her difficulties was an apparent decreased ability to retain newly-learned and relearned information. This made returning to work impossible for her and made even casual reading pleasureless.

Eventually these problems compelled the patient to investigate ECT and its 
effects on memory, on which she could find no information. She also began finding others treated with ECT with similar stories of lost memories. She felt that for patients with less intellectually demanding lives, the memory loss might never be noticed or considered a problem, but for those with a highly specialized and demanding job the results could be catastrophic for their careers. She did note, though, that her depression had resolved (16).

Coincidentally, in the fall of 1974 when the New Yorker article appeared, the American Psychiatric Association (APA) established a task force on ECT (17). The task force was instructed to review not only the scientific merits of ECT, but also to include in their study consideration of social, ethical and legal aspects. The final report, essentially supportive of ECT as a therapy, was published four years later, but during the intervening time a great deal of public attention was again focused on ECT.

A Newsweek article in early 1975, entitled "Attack on Electroshock," stated that along with psychosurgery and behavior modification, ECT had come under attack by civil libertarians and consumer groups as a hazardous and even wanton infringement on the rights of mental patients (18). A law was passed in California substantially curtailing the use of ECT by placing extensive restrictions on its application. The law was promoted by a group of former psychiatric patients, mental-health workers and radical psychiatrists called the Network Against Psychiatric Assault. A resident physician named Dr. John Friedberg became a leader of this movement, publishing a book and both popular and professional articles which were critical of ECT $(4,9,10)$.

Dr. Friedberg's book, entitled "Shock Treatment Is Not Good For Your Brain" (9), was an anecdotal account of the experiences of 15 patients who responded to a newspaper advertisement he placed soliciting stories from former patients treated with ECT. His ad was written as follows:

Electric shock therapy is not good for the brain. I would like to hear from anyone who has received these treatments here in San Francisco (9).

It seems reasonable to assume the response he received was biased against ECT.

He also authored an article in Psychology Today, that was extremely critical of both ECT and the psychiatric profession (4). He maintained the position that ECT is a totally unproven and unwarranted therapy, that it caused both brain damage and memory loss and was being foisted on an unsuspecting public by the psychiatric profession. The article is colorfully written, with accusations that ECT is more selectively given to women, that the treatment involves causing the patient to have what is otherwise considered an illness, i.e., a seizure, and that the use of ECT follows in the tradition of medical history of "beating up" the insane (4). He points out that ECT was developed during an era of political authoritarianism, the 1930's, and in the same paragraph mentions that the Germans at the time also developed the ultimate solution for mental illness: starving, beating, drugging and gassing the mentally ill to death. He goes on to describe the first use of ECT by Cerletti, in great detail, including the patient's statement, "Not another one! It's deadly!" without continuing to describe the ultimate outcome for this patient (4). 
Friedberg continues with additional anecdotal evidence against ECT. He equates the improvements of administering muscle-relaxants and anesthesia to "the flowers planted at Buchenwald." He then cites the risks involved in using these drugs on any patient (4). He states that any controlled study of ECT is impossible, and that to stimulate the results of ECT in a double-blind study one would have to "drop (the patients) on their heads" to produce a similar state of confusion, amnesia, and disorientation (4). Dr. Friedberg concludes by stating that "the practitioners of ECT are still searing the brains of the gullible, the unhappy, and the powerless. If psychotics could win lawsuits, these psychiatrists would probably be out of business." He proposes government action be taken to stop the use of ECT (4).

The response to this article was mixed, with a number of former patients writing to both agree and disagree with his conclusions. No physicians concurred with the article, and one physician described Dr. Frieberg as an individual who "deliberately assembles a mixture of fact, fiction, history and hoary references; who represents himself as an authority; and who produces an article which adds nothing to medical knowledge, but serves to frighten the undiscerning public" (19).

Dr. Frieberg also published a review article in an issue of the American Journal of Psychiatry in 1977 on the adverse effects of ECT (10). This issue contained a special section on ECT, with articles by various prominent proponents and researchers of ECT $(9,10,20,21,22,23)$. While Dr. Frieberg's assault on ECT came from a basically anecdotal base (he himself conducted no research other than the above mentioned informal poll of former patients), he apparently gained a great deal of public attention, and the psychiatric profession felt compelled to respond.

The journal's editors introduced the special section on ECT with the following:

We are aware that there will be criticism about the publication of these papers. The editors are especially concerned about their unevenness. However, in view of the widespread interest in and strong differences of opinion about the subject, we decided to give it a full airing (9).

Approximately one year later, the report of the APA task force on ECT was published which concluded that ECT was a valid, clinically effective form of therapy, had minimal side-effects (primarily transient memory loss), and few contraindications (17). The report focused on when ECT was indicated, and gave consideration to ethical and informed consent issues.

The use of ECT apparently withstood this scrutiny and was in fact bolstered by the New York Times and Time magazines, which were published the following year $(24,25)$. The New York Times article was essentially supportive, citing the APA report and individual psychiatrists' opinions on the efficacy of this treatment. One psychiatrist was quoted as saying that the apparent effectiveness of ECT, (especially in severely depressed patients who do not respond to drug therapy) may be the reason for ECT's survival in a climate of continuing public misunderstanding, distrust and apathy (24). The title of the Time article was, "Comeback for Shock Therapy? Its Unsavory Reputation May Be Changing." It pointed out that the use of ECT was 
increasing as the legal climate stabilized and the ineffectiveness of drug therapy in some patients became apparent (25).

While the use of ECT was increasing, public debate continued. An extensive critique by Hopgood, a lay author, was published in the Atlantic Monthly in 1980 (11). He began with the proposition that ECT is a barbarous, anachronistic therapy, and a passing "therapeutic enthusiasm." With apparent dismay he went on to point out that the technique is still utilized, with the blessings of the psychiatric profession as evidenced by the recent APA report (11). Hopgood continues with a discussion of the history of ECT, and as other critics have done, includes a discussion of other medical therapies and theories from the past that have fallen into disrepute and, as a result of current knowledge, seem ridiculous in retrospect. He is also critical, as others have been, of the fact that psychiatrists do not know the mechanism of action of ECT. He also describes the procedure as the "psychiatric equivalent of kicking a TV set when the picture begins to fail" and notes that might do some good, but is not based on a sophisticated knowledge of how TV sets work, and may actually do damage (11).

While the article otherwise covers no new ground in the controversy and reiterates points made years before, Hopgood does seem to identify well why ECT is so controversial. ECT may be frightening because it is a powerful technique, "clearly" he states, "capable of doing harm, and its use appears capricious as it has been applied to so many different syndromes in the past." ECT is very different from almost any other medical procedure, and to the uninformed its use portrays psychiatrists as punitive and callous (11). Hopgood does suggest that ideally ECT should be connected to a set of mental disorders that are carefully described and set apart from other disorders and are entirely comprehensible to the layman. In actuality, the psychiatric profession had moved in that direction by instituting more precise diagnostic criteria for mental illnesses (26) and designating when ECT should be used $(3,17)$.

In the political arena, the controversy continued with a petition filed in Berkeley, California for a referendum to ban the use of ECT in that city (27). The drive was led by various human-rights groups, including the previously mentioned Network Against Psychiatric Assault. One psychiatrist described the effort, which included picket lines in front of a Berkeley hospital, as an anachronistic hangover from another era of psychiatry. He said "the people who are angry now, for the most part, had ECT more than 20 years ago and most likely under unfavorable surroundings and without informed consent" (27). A referendum was passed making the use of ECT in Berkeley a crime, but was subsequently overturned in the courts (28).

Afterwards, the controversy appeared to have quieted. An article in Psychology Today in 1985 provided a favorable review of the procedure, while recognizing its tumultuous history. Interestingly, it pointed out that the public outcry and subsequent return of ECT as an effective procedure resulted in the procedure now being reserved for the relatively well-to-do in private hospitals, rather than the disadvantaged in public institutions (28). The article also discussed recent gains in the understanding of how ECT works, due to the availability of new technologies that allow for the study of neurotransmitting chemicals and receivers in the brain. 
Apparently some progress has been made in attempting to address this frequent criticism of the therapy (28).

In 1987, an article appeared in the New York Times Magazine entitled "Shock Therapy's Return to Respectability" (29) that noted on the eve of its 50th anniversary, ECT had returned as an acceptable and effective procedure. The article addressed the perception that in the past ECT was too widely and indiscriminately used, and its side-effects and effectiveness were inadequately studied. It maintained that these issues had been addressed, and that current critics had either outdated images of the procedure or made claims against it that could not be scientifically substantiated. The article did point out, though, that psychiatrists continued to frequently face suspicion and opposition from patients and families when they attempt to prescribe ECT (29). Finally, one psychiatrist was quoted making the point mentioned previously, "If you look at historical concerns over the excessive use of ECT, it seems bizarre that it is becoming a treatment of the private patient of means, not available to the poor and underinsured," i.e., those patients who formerly needed to be protected from the indiscriminate use of ECT (29).

As for the present, the public controversy over ECT seems quiescent, yet the APA has continued to show concern over both public opinion and the need for more rigorous scientific study and application of this technique. In 1990 the APA prepared and published an updated report on ECT that included standards for patient selection, application of treatment, informed consent and requirements for privileges to perform ECT (30). A discussion of the standards and extensive bibliography were presented.

The report confirmed the effectiveness of the therapy for specific psychiatric illnesses and through the standards addressed issues of indiscriminate use and proper consent. Since the APA report was published ECT has received little added public scrutiny. In an article in Newsweek on the controversy surrounding the new anti-depressant, Prozac (fluoxetine), a brief insert acknowledged ECT as a commonly utilized and effective treatment for patients with depression, mania and some forms of schizophrenia with little reference to the prior controversy surrounding this treatment (31). The article described ECT as experiencing a resurgence with an estimated 30,000-50,000 patients treated each year.

As other therapeutic methods have come and gone, ECT has remained over the 54 years since its inception. Few other therapies, however, aroused as much controversy, both professionally and in the public arena. Many factors have contributed to this controversy, as mentioned above: the use of electricity to elicit a convulsion; the use of ECT on psychiatric patients, with the questions of informed consent and possible abuse; the seemingly indiscriminate use of the procedure for a wide variety of mental illnesses; and the fact that ECT is promoted by the psychiatric "establishment." ECT has been used indiscriminately in the past, and the nature of the therapy lends itself well to dramatic representation in books, films and articles.

The psychiatric profession for the most part remains confident in the effectiveness of ECT; while insulin coma and psychosurgery have passed into disuse, ECT remains. A great deal of research has been directed towards the use of ECT, perhaps 
in large part because of the public's scrutiny of the procedure. In addition, efforts have been made by the psychiatric profession to identify more carefully when ECT is indicated, how it should be administered, and how appropriate informed consent should be obtained.

ECT now seems to be more widely accepted but may still labor under some public distrust and misunderstanding of the current use of ECT, but outright opposition may now be replaced with ignorance or indifference. Perhaps the controversy will be finally resolved when, through research, the mechanism of action of ECT is demonstrated, and when the generation of patients who were subjected to ECT during the early, pre-anesthesia days, pass away.

\section{ACKNOWLEDGEMENTS}

The author thanks Tina Walch, M.D. from the Department of Psychiatry, University of New Mexico for her encouragement, helpful comments and critical review of this manuscript.

\section{REFERENCES}

1. Kalinowsky LB: History of Convulsive Therapy. In: S Malaitz and H Sackeim (Eds) Electroconvulsive Therapy: Clinical and Basic Research Issues. Ann NY Acad Sci 462:1-4, 1986

2. Fink M: Meduna and the origins of convulsive therapy. Am J Psychiatry 1984; 141(9):10341041

3. Abrams R: Electroconvulsive therapy. Oxford, Oxford Univ. Press. 1988

4. Frieberg J: Electroshock therapy: Let's Stop Shocking the Brain, Psychology Today Ag 1975; 9:18-25

5. Plath, S: The Bell jar. NY, Harper and Row. 1971

6. Anon: Not so shocking. Time S 81947 50:42

7. Anon: Electric shock findings. Newsweek Ja 17 1949; 33:43

8. Anon: Meeting on minds. Newsweek Je 6 1949; 47-49

9. Friedberg, J: Shock treatment is not good for your brain. San Francisco, Glide Pub, 1976

10. Friedberg, J: Shock treatment, brain damage, and memory loss: A neurological perspective. Am J Psychiatry 1977; 134(9):1010-1014

11. Hapgood, F: Electroshock; The Unkindest Therapy Of All. Atlantic Ja 1980; 245:53-59

12. Anon: Eagleton's Own Story of His Health Problems. US News Ag 7 1972; 73:16-17

13. Anon: The Most Common Mental Disorder. Time Ag 7 1972; 100:16-17

14. Anon: Evaluating Eagleton. Time Ag 14 1972; 100:41

15. Anon: Depression and Electroshock. Newsweek Ag 7 1972; 80:20

16. Roueche, B: Annals of Medicine; Empty as Eve. New Yorker S 9 1974; 50:84

17. Task Force on Electroconvulsive Therapy: Electroconvulsive Therapy. Wash, DC, Am Psychiatric Assoc, 1978

18. Clark, M, Lubenow, G: Attack on Electroshock. Newsweek Mr 17 1975; 85:86

19. Mayberg, DM: Letter to the Editor. Psychology Today D 1975, 9:13

20. Squire LR: ECT and memory loss. Am J Psychiatry 1977; 134(9):997-1001 
21. Greenblatt M: Efficacy of ECT in affective and schizophrenic illness. Am J Psychiatry 1977; 134(9): 1001-1005

22. Salzman C: ECT and Ethical Psychiatry. Am J Psychiatry 1977; 134(9):1006-1009

23. Frankel, FH: Current Perspectives on ECT: a disçussion. Am J Psychiatry 1977; 134(9):10141019

24. Scarf, M: Shocking the Depressed Back to Life. NY Times Mag Je 17 1979; p32-34+

25. Anon: Comeback for Shock Therapy? Time N 19 1979; 114:76

26. American Psychiatric Association: Diagnostic and Statistical Manual of Mental Disorders, Third Ed, Revised. Wash, DG, Am Psychiatric Assoc., 1987

27. Clark M, Scmidt M, Hager M: Voting on Electroshock. Newsweek O 25 1982; 100:105

28. Sacheim HA: The Case for ECT. Psychology Today Je 1985; 19:36-40

29. Squire S: Shock Therapy's Return to Respectability. NY Times Mag N 22 1987; p 78-79+

30. Task Force on Electroconvulsive Therapy: The Practice of Electroconvulsive Therapy: Recommendations for Treatment, Training and Privileging. Wash DC, Am Psychiatric Association, 1990

31. Anon: Shock Treatment Returns. Newsweek Mr 26 1990; 115:44 